pulmonary artery catheters, only a bad workman blames his tools. In many conditions the pulmonary artery catheter is an indispensable tool, which I do not want to lose. We should grasp the opportunity to re-evaluate the way we use this tool, not discard it.

NEIL SONI

Chelsea and Westminster Hospital,

London SW10 9NH

1 Connors A, Speroff T, Dawson N, Thomas C, Harrell FE Jr, Wagner D, et al. The effectiveness of right heart catheterization in the initial care of critically ill patients. $\mathscr{T}$ AMA 1996;276: of right

Dalen J, Bone R. Is it time to pull the pulmonary artery catheter? YAMA 1996;16:916-8.

3 Isaacson IJ, Lowdon JD, Berry AJ, Smith RB, Knos GB, Weitz FI, et al. The value of pulmonary artery and central venous monitoring in patients undergoing abdominal aortic reconstructive surgery: a comparative study of two selected, randomized groups. I Vasc Surg 1990;12: 754-60.

4 Gore J, Goldberg R, Spodick D, Alpert J, Dalen J. A community wide assessment of the use of pulmonary artery catheters in patients with acute myocardial infarction. Ches 1987;98:1331-5.

5 Hayes M, Timmins A, Yau E, Palazzo M, Hinds C, Watson D. Elevation of systemic oxygen delivery in the treatment of critically ill patients. N Engl F Med 1994;330:1717-22.

6 Gattinoni L, Brazzi L, Pelosi P, Latini R, Tognoni G, Pesenti A, et al.A trial of goal orientated hemodynamic therapy in critically ill patients. $N$ Engl 9 Med 1995;333:1025-32.

7 Mimoz O, Rauss A, Rekik N, Brun Buisson C, Lemaire F, Brochard L. Pulmonary artery catheterization in critically ill patients: a prospective analysis of outcome changes associated with catheter-prompted changes in therapy. Crit Care Med 1994;22.573-9.

8 Boyd $\mathrm{O}$, Grounds M, Bennett E. A randomized clinical trial of the effect of deliberate perioperative increase of oxygen delivery on mortality in high risk surgical parents. $\mathcal{Y} A M A$ 1993;270:2699-707.

9 Del Guercio $L$, Cohn J. Monitoring operative risk in the elderly. $¥ A M A 1980 ; 243: 1350-5$.

10 Older $P$, Smith $R$, Courtney $P$, Hone $R$. Preoperative evaluation of cardiac failure and ischaemia in elderly patients by cardiopulmonary exercise testing. Chest 1993;104:701-4.

11 Berlauk JF, Abrams JH, Gilmour IJ, O'Connor SR, Knighton DR, Cerra FB. Ann Surg 1991;214:289-97.

12 Shoemaker WC. What should be monitored? The past, present, and future of physiological monitoring. Clin Chem 1990;36:1536-43.

13 Shoemaker W, Bland R, Appel P. Therapy of critically ill postoperative patients based on outcome prediction and prospective clinical trials. Surg Clin North Am 1985;65:811-33.

14 Shoemaker W, Appel P, Kram H, Waxman K, Lee T. Prospective trial of supranormal value of survivors as therapeutic goals in high risk surgical parents. Chest 1988;94:1176-85.

\title{
Global competition in health care
}

\author{
American managed care companies begin to look for international markets
}

Your software may come from the United States, your computer from Singapore, your car from Germany or Japan, and your wine from Chile, but no matter where you are reading this your health care is probably provided from your own country. That may be about to change, particularly if you live in the developing world.

Earlier this month the leaders of United States managed health care plans met in Mexico City to look at the opportunities for doing business internationally. The meeting was organised by the American Association of Health Plans and the Academy for International Health Studies. As one delegate said, the rhetoric may have been about learning from other countries but most of the Americans at the meeting were interested in selling. Workshops looked at "market opportunities" in Israel, Korea, Venezuela, Canada, Mexico, Russia, France, Singapore, Brazil, New Zealand, Puerto Rico, Australia, South Africa, and Argentina. Britain was probably absent from the list because its financially constrained health care system provides little room for profit and because many of the methods of managed care are already being used.

The meeting began by looking at general economic trends, and the main development at the end of the 20th century is that global competition is becoming the norm in an increasing number of economic sectors. Tom Friedman, the New York Times' Pulitzer prize winning foreign affairs columnist, said that countries were forced to open their economies to global competition. This increases competitiveness, and various consequences follow. Firstly, the international capital markets restrict governments' room to manoeuvre on economic issues. Secondly, because of this, different political parties in a country come much closer together in their policies. Thirdly, what happens in a country is increasingly driven by what is important for business: the United States did not take a hard line with China on human rights because American business did not want to lose markets, but it did take strong action over intellectual property because that was important to the business community. Bill Gates, the chief executive of Microsoft, has met the prime minister of China more often than has Bill Clinton. Fourthly, the gap between the haves and the have nots grows: the haves do well because they can reap huge rewards from success in the global market place, whereas the have nots are shut out completely.

The businessmen who run the for profit managed health care plans in the United States see no reason why they should not follow the path of their colleagues in other businesses and compete globally. Indeed, they may have to. Wall Street expects them to keep growing, which means signing up more people to their plans. And, as one chief executive of a health plan put it, "We are soon going to run out of people in the United States." Managed care plans already cover 100 million Americans.

What is it that managed care plans might have to sell? In essence, it is the capability of getting more for less (p 772). Managed care is an elusive and fast changing concept, but one way to define it, said Joe White from the Brookings Institute in Washington, is that it is about managing individual episodes of care in order to reduce costs and possibly raise quality. Managed care comes in three general forms. First is third party managed care, where payers set rules on treatment to be followed by providers not owned by them. Secondly, prepaid comprehensive plans register people with an organisation and costs are controlled from within by collegiate pressure; these are the health maintenance organisations exemplified by Kaiser Permanente. Thirdly, there are plans run by "risk bearing gatekeepers": these are usually doctors, who decide which patients need further care but who must also bear the financial or legal consequences of under- or over-referral for treatment. This is a cheaper and more flexible form of managed care and is the type that is growing most rapidly. It has similarities with general practitioner fundholding in Britain. All these forms of managed care use a broad range of management techniques to reduce costs. It is these techniques that may prove most exportable.

Solid evidence that schemes do reduce costs and raise quality is lacking, and academic study of the health plans is difficult because they are changing so fast. But the assumption in the United States seems to be that the proliferation of managed care plans has stopped American health care costs from rising for the first time in two decades. ${ }^{1}$

Does the world need what these many managed care plans have to offer? Armeane Choksi, vice president of the human development division of the World Bank, clearly thinks it does-and that the opportunities are greatest in developing countries. In the past 10-15 years, said Choksi, development has come to be seen as a matter for the private sector rather than governments, and health is a key part of development. The economies of most developing countries are growing much faster than those of developed countries, primarily because of private investment. In most developing countries the private health sector is proportionally much bigger than in 
developed countries; and in many of these countries-for example, Malaysia, Indonesia, and Bangladesh-the private sector is expanding. The "old reason" for favouring public rather than private health care was, said Choksi, equity; but in most public systems inequalities remain extreme, and, particularly because health spending has been concentrated in city hospitals, the rural poor have often been subsidising the urban wealthy. The World Bank is now concentrating on public and primary health care for the poor. It believes in increased private health care for the wealthy in order to release public money for the poor and to raise efficiency and quality in the private sector. There are, Choksi concluded, big opportunities:
"Managed care holds the biggest hope for developing health services in the developing world."

So perhaps managed health care-which has emerged from a country with one of the world's most irrational health care systems - will end up being exported around the world. Just as more and more of us are fed by American fast food chains, so many of us may receive our health care in some way through American managed health care plans.

RICHARD SMITH Editor, $B M \mathcal{F}$

1 Ginsburg PB, Pickreign JD. Tracking health care costs. Health Affairs 1996; Fall: 140-9.

\section{Enjoy your fruits and vegetables}

\section{Eating fruit and vegetables protects against the common chronic diseases of adulthood}

When I was young my mother repeatedly admonished me to eat my fruits and vegetables. She had a valid point: the health benefits of fruits and vegetables are remarkably consistent across epidemiological studies. Perhaps the most convincing evidence relates to the risk of cancer. Data from various casecontrol and cohort studies strongly indicate that diets rich in fruits and vegetables reduce the incidence of several common neoplasms, especially of the respiratory and digestive tract. ${ }^{1-3}$ The epidemiological data are in accord with biological mechanisms, as known phytochemicals can alter almost every stage of carcinogenesis. ${ }^{4}$ Fewer data exist about cardiovascular disease, but recent observational studies show inverse associations of intake of fruits and vegetables with cardiovascular mortality ${ }^{5}$ and the incidence of myocardial infarction ${ }^{6}$ and stroke. ${ }^{7}$ The results of these observational studies complement evidence from cross-cultural studies, such as the Seven Countries Study, in which mortality from all causes and cardiovascular diseases were lowest in countries with traditional plant based diets. $^{8}$

In this context, the study of Key et al on p 775 adds important information. ${ }^{9}$ It is a cohort study of health conscious individuals, whose mortality rates are, as one would expect, much less than those of the general population. The principal findings were $21-32 \%$ reductions in mortality from all causes, ischaemic heart disease, and cerebrovascular disease among daily consumers of fresh fruit compared with subjects consuming less fruit. The authors also found inverse associations of similar magnitude between fresh fruit intake and deaths from cancer, although the confidence intervals were wider. An asset of this study is its focus on foods, rather than specific nutrients. Dietary advice based on foods-"eat more fresh fruit"-is easier to understand than advice based on nutrient intake- “increase your intake of flavonoids." Also, trying to isolate a single active nutrient from the complex interplay of substances contained in foods can be fraught with difficulty. For example, the role of the antioxidant $\beta$ carotene is now unclear: recent randomised trials have not shown benefit from supplements, despite evidence from numerous observational studies that consuming foods high in $\beta$ carotene is beneficial. ${ }^{10}$ One possible explanation is that $\beta$ carotene lacks activity itself but serves as a marker for other protective dietary factors found in these foods.

Key et al point out some limitations of their study, including its inability to detect change of diet over time. In addition, their method of dietary assessment was blunt, and disease specific outcomes based on death certificates may be inaccurate. With such opportunities for misclassification of exposure and outcome, which would tend to obscure associations, it is remarkable that they uncovered the relations they did.
Furthermore, as in any observational study, we must be concerned about confounding. For example, fruit eaters are probably more health conscious than non-fruit eaters, even within this cohort. The authors controlled for smoking, but they did not have data on other potentially confounding factors, such as physical activity, body mass index, socioeconomic status, and health beliefs.

The best way to control for confounding is through a randomised controlled trial. As with many lifestyle changes, however, conducting a large, long term trial of the health benefits of fruits and vegetables would be difficult. Observational studies necessarily provide most of the information about health benefits of foods and food groups. The results of Key et al regarding intake of fruits, and to a lesser extent, raw salad and wholemeal bread, are consistent with the large body of evidence from observational studies about the health benefits of plant based diets, especially those high in fruits and vegetables.

The challenge now is to increase the consumption of fruits and vegetables among children and adults in Western societies. Since the industrialisation of agriculture in the past century, residents of Western countries have disproportionately increased meat and dairy consumption. This trend is especially true in the US and UK compared with Mediterranean countries. ${ }^{11}$ Recent data from the US indicate an average intake of fruits and vegetables of three to four servings a day, substantially less than the five to nine servings recommended by the US Department of Agriculture. ${ }^{12}$

Numerous barriers exist to increasing consumption of fruits and vegetables. The popularity of fast food among some children means that their commonest vegetable is fried potatoes. ${ }^{13}$ Among poorer populations, especially in northern cities, fresh fruits and vegetables are less available and more expensive. In addition, increased demand for fresh produce may mean less regulation of agricultural practices and transportation over greater distances, with an attendant increase in foodborne illnesses. ${ }^{14}$ Fortunately, frozen fruits and vegetables may be as healthful as fresh ones.

These barriers present opportunities for innovative programmes. For example, the US National Cancer Institute sponsors a nationwide initiative to increase consumption of fruits and vegetables to at least five servings per day. This initiative includes promotional efforts in retail stores; a national media programme highlighting an annual " 5 a day" week; and education through community channels such as schools, workplaces, and food assistance programmes. ${ }^{12}$

Clinicians may also help to improve the diets of their patients. Research will clarify what strategies are effective and practical in the clinical setting. For example, techniques based 